\title{
ARMAZENAMENTO DE SEMENTES DE PASSIFLORA SUBEROSA
}

\author{
Lourival Palmeira Goncalves Netoㅜ; Claudinéia Regina Pelacani ${ }^{2}$; Verônica de \\ Jesus Boaventura ${ }^{3}$. \\ 1. Bolsista PIBIC/FAPESB, Graduando em Agronomia, Universidade Estadual de Feira de Santana, e-mail: \\ lourivalpgneto@yahoo.com.br \\ 2. Orientadora, Departamento de Ciências Biológicas, Universidade Estadual de Feira de Santana, e-mail: \\ claudineiapelacani@gmail.com \\ 3. Doutoranda em Recursos Genéticos Vegetais, Departamento de Ciências Biológicas, Universidade Estadual de \\ Feira de Santana, e-mail: vel_jb@yahoo.com.br
}

PALAVRAS-CHAVE: deterioração; maracujá; germinação.

\section{INTRODUÇÃO}

Espécies silvestres de maracujazeiro como Passiflora suberosa vêm chamando a atenção para estudos científicos por apresentar caracteres agronômicos importantes que podem ser introduzidos no maracujá comercial através do melhoramento genético.

O maracujá é propagado preferencialmente por sementes, no entanto estudos com outras espécies de passiflora constataram baixa germinação e desuniformidade causado por dormência (VASCONCELOS et al. 2005). O armazenamento surge como uma alternativa para superação da dormência (MELETTI et al., 2002; ZUCARELLI et al., 2007), entretanto, sementes de algumas espécies de maracujazeiro perdem a viabilidade durante o armazenamento sendo necessários estudos para protocolar e monitorar a longevidade e vaibilidade das sementes

O objetivo do trabalho foi monitorar a taxa de deterioração de sementes de Passiflora suberosa em diferentes umidades relativas e temperaturas (envelhecimento controlado) durante o armazenamento de sementes.

\section{METODOLOGIA}

O trabalho foi realizado no Laboratório de Germinação (LAGER), localizado na Unidade Experimental Horto Florestal da Universidade Estadual de Feira de Santana, Bahia (UEFS).

Foram utilizadas sementes de Passiflora suberosa provenientes do Banco Ativo de Germoplasma pertencente à Embrapa Mandioca e Fruticultura, Cruz das Almas, Bahia. Aproximadamente 250-500 sementes íntegras de P. suberosa foram colocadas em câmaras contendo ao fundo solução saturada de Cloreto de zinco $\left(\mathrm{ZnCl}_{2}\right)$ e Cloreto de sódio $(\mathrm{NaCl})$ simulando ambiente de baixa e alta umidade relativa, 5\% e $75 \%$, respectivamente. Em seguida cada câmara foi disposta nas temperaturas de armazenamento $5{ }^{\circ} \mathrm{C}$ e $35{ }^{\circ} \mathrm{C}$. A partir do inicio do armazenamento, foi elaborado um calendário de períodos de monitoramento das sementes, sendo, por um período de 12 meses.

Para a condição de baixa UR (5\%), o acompanhamento da viabilidade ocorreram em intervalos de 8 semanas (60 dias) e o acompanhamento das sementes armazenadas a alta UR (75\%) em intervalos de 4 semanas (28 dias). Uma subamostra de cada tratamento $(\mathrm{n}=50)$, foram retiradas e submetidas aos seguintes procedimentos: a) pré-tratamento 
mecânico (M); b) processo de assepsia; c) semeadura em recipientes (300 mL) contendo substrato comercial e enterradas a uma profundidade média de $2 \mathrm{~cm}$, irrigadas diariamente e mantidas em ambiente tipo telado (redução de $60 \%$ da luz direta) e avaliadas durante um período de 30 dias. A partir daí foi determinada a taxa de emergência de plântulas (\%), considerando plântula normal aquelas com o aparecimento e expansão dos cotilédones acima da superfície do substrato. Todas as plântulas emergidas foram contabilizadas e utilizadas para análise do vigor.

Após a última contagem e a retirada das plântulas dos recipientes foram realizadas medidas do comprimento da parte aérea e raiz com auxilio de régua graduada $(\mathrm{cm})$, o diâmetro do caule $(\mathrm{mm})$ utilizando paquímetro digital e a contagem do numero de folhas emitidas. Em seguida foram obtidos o peso da massa fresca $(\mathrm{mg})$ da parte aérea e raiz, e depois de secas em estufa com circulação de ar a $60,5^{\circ} \mathrm{C}$, o peso da massa seca (mg).

O delineamento foi inteiramente casualizado sendo o numero total de 50 sementes por tratamento com 5 repetições e 10 sementes por repetição. Os dados foram submetidos a a analise de variância e teste de média comparando os tratamentos com o as sementes controle mantidas integras e em condições ambiente.

\section{RESULTADOS E DISCUSSÃO}

$\mathrm{Na}$ figura 1 podemos observar o comportamento de sementes de Passiflora suberosa nas condições de armazenamento testadas. De modo geral, as sementes apresentaram aumento da viabilidade (\% emergência) quando armazenadas em baixas temperaturas ( 5 ${ }^{\circ} \mathrm{C}$ ) tanto em UR alta $(\mathrm{NaCl})$ e baixa $\left(\mathrm{ZnCl}_{2}\right)$ quando comparadas ao T0 (controle). Verificou-se ainda que a condição de alta UR favoreceu o aumento de vigor das sementes nos primeiros 120 dias do armazenamento, mantendo a germinabilidade acima de $50 \%$ do valor máximo, enquanto que em condições de baixa UR detectou-se a perda gradativa do potencial de emergência de plântulas.

Partindo do pressuposto que o sucesso do armazenamento e a manutenção do vigor podem estar relacionados aos procedimentos de coleta e de beneficiamento das sementes, os resultados observados apontam que as sementes desse genótipo mostram certa sensibilidade ou perdem seu potencial máximo de germinação e vigor em ambientes com restrição de umidade e alta temperatura, e que a temperatura baixa associada com conteudo de água adequado mantem a longevidade das sementes. 


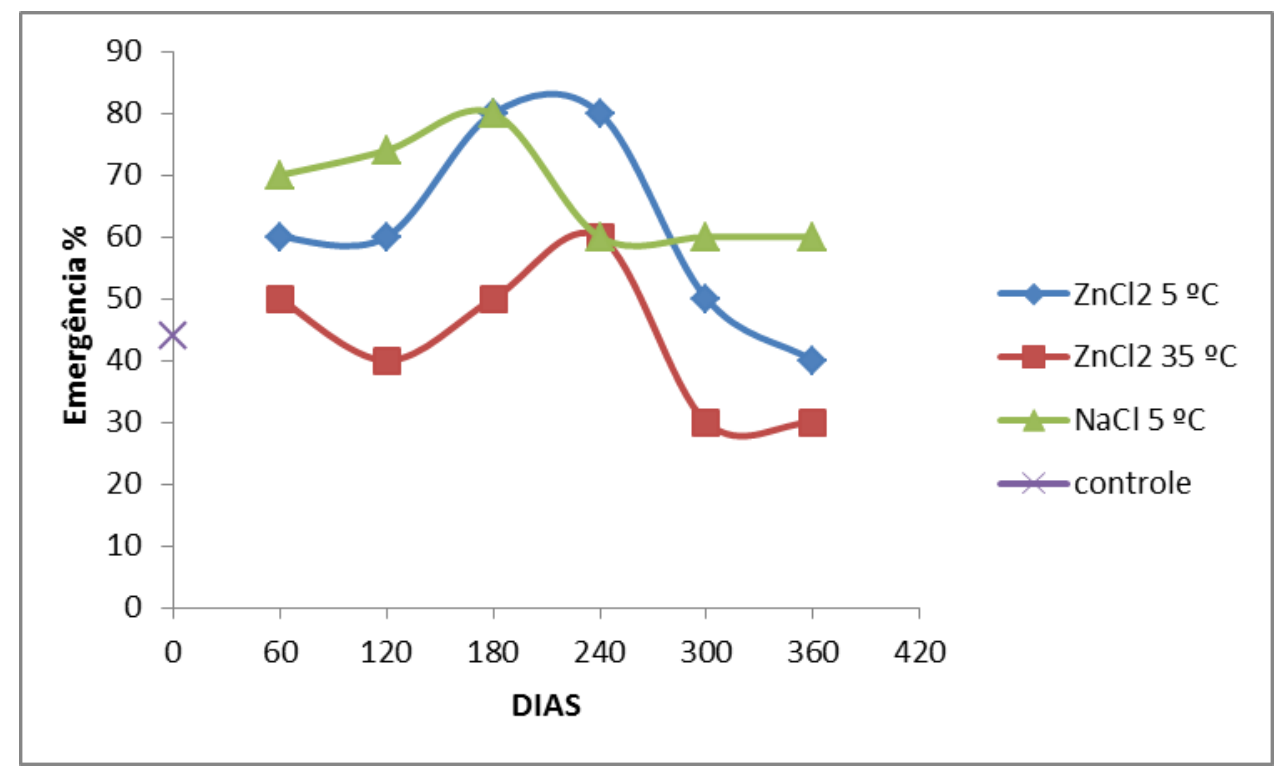

Figura 1. Porcentagem de emergência de Passiflora suberosa, submetidas ao armazenamento em diferente umidade relativa e temperatura.

Semelhante resposta no vigor das sementes foi observada para o Índice de velocidade de emergência (IVE) e Tempo médio de emergência (TME) à medida que aumentava o período de armazenamento das sementes. Os maiores valores de IVE foram observados quando as sementes eram armazenadas nas temperaturas mais baixas, independente da UR testada. Contudo, a velocidade da emergência foi reduzida à medida que o período de armazenamento era maior, o que justifica o aumento do TME. Essa redução do potencial de viabilidade refletiu ainda na taxa de emergência, uma resposta típica de semente deteriorando, cujas sementes para germinarem requerem maior período de tempo (dias) (Tabela 1).

Tabela 1- Emergência, índice de velocidade de emergência (IVE) e tempo médio de emergência (TME) a partir de sementes armazenadas em diferentes umidades relativa e temperatura, durante o período de 360 dias.

\begin{tabular}{lccc|ccc|ccc}
\hline \multirow{2}{*}{ Dias } & \multicolumn{3}{c|}{$\%$ Emergência } & \multicolumn{3}{c|}{$\mathrm{IVE}$} & \multicolumn{3}{c}{$\mathrm{TME}^{\left(\operatorname{dias}^{-1}\right)}$} \\
\cline { 2 - 10 } & $\mathrm{NaCl}$ & $\mathrm{ZnCl}_{2}$ & $\mathrm{ZnCl}_{2}$ & $\mathrm{NaCl}$ & $\mathrm{ZnCl}_{2}$ & $\mathrm{ZnCl}_{2}$ & $\mathrm{NaCl}$ & $\mathrm{ZnCl}_{2}$ & $\mathrm{ZnCl}_{2}$ \\
& $5^{\circ} \mathrm{C}$ & $5^{\circ} \mathrm{C}$ & $35^{\circ} \mathrm{C}$ & $5^{\circ} \mathrm{C}$ & $5^{\circ} \mathrm{C}$ & $35^{\circ} \mathrm{C}$ & $5^{\circ} \mathrm{C}$ & $5^{\circ} \mathrm{C}$ & $35^{\circ} \mathrm{C}$ \\
\hline 60 & 70 & 60 & 50 & 0.546 & 0.530 & 0.355 & 11.3 & 11.0 & 12.8 \\
120 & 74 & 60 & 40 & 0.510 & 0.446 & 0.272 & 13.5 & 13.67 & 15.0 \\
180 & 80 & 80 & 50 & 0.527 & 0.498 & 0.300 & 13.0 & 13.30 & 15.2 \\
240 & 60 & 80 & 60 & 0.510 & 0.500 & 0.272 & 13.2 & 12.97 & 14.9 \\
300 & 60 & 50 & 30 & 0.498 & 0.240 & 0.216 & 15.0 & 18.4 & 16.0 \\
360 & 60 & 40 & 30 & 0.263 & 0.255 & 0.210 & 19.8 & 20.0 & 16.0 \\
\hline
\end{tabular}

Plântulas advindas de sementes não armazenadas apresentaram 5.2 centímetros de comprimento da parte aérea, 12.3 centímetros em comprimento de raiz e 0.4413 gramas de massa seca, sendo os valores superiores quando comparado às plântulas obtidas após o armazenamento (Tabela 2). De modo geral o armazenamento não favoreceu para o 
incremento do vigor de plântulas de Passiflora. Houve algum acréscimo no comprimento da raiz e na parte aérea de plântulas, mais especificamente daquelas provenientes de semente mantidas em UR alta (75\%). De modo contrário as sementes foram bastante sensitivas aos métodos de armazenamento o que pode ter causado danos relacionados com a deterioração de reservas para crescimento das mesmas, principalmente quando o período de armazenamento era prolongado.

Comparativamente, o ambiente de alta UR e baixas temperaturas mostrou favorecer o vigor de plântula de maracujá quando comparado com o ambiente de baixa umidade $\left(\mathrm{ZnCl}_{2}\right)$ sob a mesma temperatura. Para essas sementes, a condição de armazenamento que favoreça a manutenção ou elevação da viabilidade das sementes deverá ser mais bem investigada, embora esse trabalho tenha mostrado indícios importantes sobre o melhor comportamento em ambiente mais úmido e em baixas temperaturas (Tabela 2).

Tabela 2- Crescimento da parte aérea $(\mathrm{cm})$, de raiz $(\mathrm{cm})$ e massa seca de plântulas advindas de sementes armazenadas em diferente umidade relativa e temperatura.

\begin{tabular}{llllllllll}
\hline \multirow{2}{*}{ Dias } & \multicolumn{3}{c}{ Comprimento parte aérea } & \multicolumn{3}{c}{$\begin{array}{c}\text { Comprimento raiz } \\
\mathrm{cm}\end{array}$} \\
\cline { 2 - 10 } & $\mathrm{NaCl}$ & $\mathrm{ZnCl}_{2}$ & $\mathrm{ZnCl}_{2}$ & $\mathrm{NaCl}$ & $\mathrm{ZnCl}_{2}$ & $\mathrm{ZnCl}_{2}$ & \multicolumn{3}{c}{$\begin{array}{c}\text { Massa seca plantula } \\
\mathrm{g}\end{array}$} \\
& $5^{\circ} \mathrm{C}$ & $5^{\circ} \mathrm{C}$ & $35^{\circ} \mathrm{C}$ & $5^{\circ} \mathrm{C}$ & $5^{\circ} \mathrm{C}$ & $35^{\circ} \mathrm{C}$ & $5^{\circ} \mathrm{C}$ & $5^{\circ} \mathrm{C}$ & $35^{\circ} \mathrm{C}$ \\
\hline 60 & 5.8 & 3.1 & 2.6 & 6.1 & 4.1 & 6.2 & 0.0978 & 0.0604 & 0.0191 \\
120 & 3.4 & 2.8 & 3.8 & 9.8 & 8.3 & 8.2 & 0.1664 & 0.0381 & 0.0279 \\
180 & 3.3 & 4 & 3.2 & 3.4 & 5.4 & 5.2 & 0.1204 & 0.1516 & 0.0571 \\
240 & 3 & 3.2 & 3.4 & 8.7 & 6.7 & 7.3 & 0.1147 & 0.1120 & 0.0689 \\
300 & 3 & 2.7 & 2.6 & 6.1 & 4.2 & 3.6 & 0.0938 & 0.0483 & 0.0507 \\
360 & 3 & 3.2 & 3 & 7.5 & 1.0 & 3.7 & 0.0568 & 0.0785 & 0.0845 \\
\hline
\end{tabular}

\section{CONCLUSÃO}

Neste estudo inicial, a deterioração controlada de sementes reflete a perda gradativa do potencial de viabilidade de Passiflora suberosa e que o armazenamento em condições de alta UR e baixa temperatura favorece para a emergência de plântulas e produção de mudas.

\section{REFERÊNCIAS}

VASCONCELOS, M.A. da S; SILVA, A.C.; REIS, F. de O. Ecofisiologia do maracujazeiro e implicações na exploração diversificada. In: FALEIRO, F. G.; JUNQUEIRA, N. T. V.; BRAGA, M. F. (Eds.). Maracujá: germoplamas e melhoramento genético. Brasília, DF: Embrapa Cerrados, p.293- 314, 2005.

ZUCARELLI, V.; FERREIRA, G.; FERRARI, T.B.U.; AMARO, A.C.E.A. Desenvolvimento de mudas de Passiflora cincinnata Mast. com uso de reguladores vegetais. Revista Brasileira de Biociências, Porto Alegre, v.5, n.2, p.846-848, 2007.

MELETTI, L. M. M.; FURLANI, P.R.; ALVARES. V.; SOARES-SCOTT, M.D.; BERNACCI, L.C.; FILHO, J.A.A. Novas tecnologias melhoram a produção de mudas de maracujá. O Agronômico, Campinas, v.54, n.1, p.30-33, 2002. 